Jurnal Informatika dan Rekayasa Perangkat Lunak (JATIKA)
Vol. 1, No. 1, June 2020, page. 1-8

\title{
SISTEM PENDUKUNG KEPUTUSAN PENGUJIAN KELAYAKAN ANGKUTAN UMUM PADA DINAS PERHUBUNGAN LAMPUNG TENGAH
}

\author{
Decsa Putra Ashari ${ }^{1}$, Suaidah ${ }^{2}$ \\ S1 Informatika, Universitas Teknokrat Indonesia ${ }^{1}$ \\ S1 Informatika, Universitas Teknokrat Indonesia ${ }^{2}$ \\ decsaputra1@gmail.com¹, suaidah@teknokrat.ac.id²
}

Received: (Mei 2020)Accepted: (Juni 2020) Published: (Juni 2020)

\begin{abstract}
Road transportation is the movement between people or goods from one place to another. The current problem is still experiencing obstacles in determining the results of the decision on the feasibility of public transportation testing. The many criteria that must be assessed make testers have difficulty in making the test results of the vehicle. A mistake that often occurs is when the vehicle is not roadworthy but the vehicle is still operating. Based on these problems, the author will make a decision support system application for testing the feasibility of public transportation using the Analytical Hierarchy Process (AHP) method. The system is to assist testers in testing public transportation, this system is made web-based. The process handled in this system is the decision making process in determining physical testing, the process of determining the type of physical testing action that must be carried out based on the results of the analysis of the calculation of criteria that are valued. The results of the system are built in the form of decision support information on the physical testing of priority vehicles along with recommendations for the type of action that must be taken. Testing in this study uses ISO / IEC 25010, testing is done as an evaluation of software quality, aspects of functionality, aspects of efficiency, and aspects of operability. The total score resulting from this test is the functionality aspect is $85 \%$, the efficiency aspect is $73.3 \%$ and the operability aspect is $80 \%$
\end{abstract}

Keywords: SPK, Public Transport Feasibility, AHP, ISO /IEC 25010.

\begin{abstract}
Abstrak
Angkutan Jalan merupakan perpindahan antara manusia atau barang dari satu tempat ke tempat yang lainnya.Permasalaan yang terjadi saat ini masih mengalami hambatan dalam menentukan hasil keputusan pengujian kelayakan angkutan umum.Banyaknya kriteria yang harus di nilaimembuat penguji mengalami kesulitan dalam membuat hasil pengujian kendaraan tersebut. Kesalahan yang sering terjadi yaitu, ketika kendaraan tersebut tidak layak jalan tetapi kendaraan tersebut masih saja beroperasi. Berdasarkan masalah tersebut, penulisakan membuat aplikasi sistem pendukung keputusan pengujian kelayakanangkutan umum menggunakan metode Analytical Hierarchy Process (AHP). Sistem tersebut guna membantu penguji dalam menguji angkutan umum, sistem ini dibuat berbasis web. Proses yang ditangani dalam sistem ini adalah proses pengambilan keputusan dalam menentukan pengujian fisik, proses penentuan jenis tindakan pengujian fisik yang harus dilakukan berdasarkan hasil dari analisis perhitungan kriteria yang di nilai. Hasil dari sistem yang dibangun berupa informasi pendukung keputusan terhadap pengujian fisik kendaraan yang menjadi prioritas beserta rekomendasi jenis tindakan yang harus dilakukan.Pengujian dalam penelitian ini menggunakan ISO /IEC 25010, Pengujian dilakukan sebagai evaluasi kualitas software, aspek functionality, aspek efficiency, dan aspek operability. Skor total yang dihasilkan dari pengujian ini yaitu aspek functionality adalah $85 \%$, aspek efficiency adalah 73,3\% dan aspek operability adalah $80 \%$.
\end{abstract}

Kata Kunci: SPK, Kelayakan Angkutan Umum, AHP, ISO /IEC 25010. 


\section{To cite this article:}

Suaidah, Decsa Putra Ashari. (2020). Sistem Pendukung Keputusan Pengujian Kelayakan Angkutan Umum Menggunakan Metode Analytical Hierarchy Process. Jurnal Informatika dan Rekayasa Perangkat Lunak, Vol(1), 1-8.

\section{PENDAHULUAN}

Sistem Pendukung Keputusan (SPK) merupakan sebuah aplikasi yang dapat memberikan beberapa solusi pemecahan masalah dengan kondisi permasalahan semi terstruktur dan tak terstruktur. Aplikasi dapat diterapkan untuk membantu user dalam pengambilan keputusan dalam situasi semi terstruktur dan situasi yang tidak terstruktur, dimana tidak ada satu orangpun tahu secara pasti bagaimana keputusan seharusnya dibuat (Turban, 2005). Dalam penelitian sebelumnya menjelaskan bahwa Sistem Pendukung Keputusan dengan menggunakan metode Analytical Hierarchy Process (AHP) secara umum memiliki manfaat untuk memudahkan dalam pengambilan keputusan yang menitik beratkan pada hirarki dan juga pembobotan pada (Taufiq \& Fahrozi, 2016).

Peraturan Pemerintah Nomor 74 tahun 2014 tentang Angkutan Jalan Angkutan merupakan perpindahan antara manusia atau barang dari satu tempat ke tempat yang lainnya menggunakan kendaraan di ruang lalu lintas jalan. Tujuan pelayanan angkutan umum adalah memberikan pelayanan ke masyarakat yang aman, cepat, nyaman, dan murah yang mobilitasnya semakin meningkat, terutama pelayanan bagi para pekerja dalam menjalankan kegiatannya harus maksimal.Peran angkutan umum yaitu melayani kepentingan mobilitas masyarakat, pengendalian lalu lintas, penghematan energi dan pengembangan wilayah.Jenis angkutan umum dibagi berdasarkan kualitas dan kapasitas (Warpani, 2002).

Pengujian yang sedang berlangsung masih mengalami hambatan dalam menentukan hasil keputusan pengujian kendaraan amgkutan umum.Banyaknya kriteria yang harus di nilai membuat penguji mengalami kesulitan dalam membuat hasil pengujian kendaraan tersebut.Dalam melakukan analisis dari penilaian tersebut, masih terjadi kesalahan dalam menentukan hasil akhir keputusan.Kesalahan yang sering terjadi yaitu, ketika kendaraan tersebut tidak layak jalan tetapi kendaraan tersebut masih saja beroperasi.

Berdasarkan permasalahan yang penulis merancang sebuah aplikasisistem pendukung keputusan yang nantinya dapat membantu penguji dalam menentukan pengujiankendaraan angkutan umum.Pengujian dilakukan menggunakan Analytical Hierarchy Process (AHP) karena memiliki kelebihannya dibandingkan dengan metode lain yang terletak pada kemampuannya untuk memecahkan masalah yang multi objektivitas dengan multi kriteria. Tujuan dari penelitian ini adalah untuk memberikan rekomendasi kepada penguji untuk menentukan Pengujian Angkutan Umum dan dapat meminimalisir kesalahan dalam memutuskan hasil pengujian.

\section{TELAAH PUSTAKA}

Analytical Hierarchy Process (AHP)

Analytical Hierarchy Process (AHP) dibuat untuk mengambarkan cara berpikir seperti pengguna sebenarnya. Aspek yang di nilai yaitu melalui aspek kuantitatif dan kualitatif keputusan yang akan dipertimbangkan. AHP dapat mengurangi dan menghasilkan keputusan yang kompleks menjadi sebuah rangkaian satu-satu pada perbandingan yang kemudian memberikan hasil yang akurat sesuai kebutuhan.AHP juga menggunakan skala rasio untuk bobot kriteria dan scoring alternatif yang menambahkan untuk pengukuran presisi.(Magdalena, 2012)

\section{Prinsip Analytical Hierarchy Process (AHP)}

Menurut Kusrini, 2007 AHP mempunyai prinsip yang dasarnya langkah-langkah meliputi berikut ini:

1. Membuat Hierarki

Sistem yang kompleks dipecah menjadi bagian-bagian pendukung dan disusun secara hierarki.

2. Penilaian Kriteria dan Alternatif

Penilaian dan definisi pendapat kualitatif dari skala perbandingan bisa diukur menggunakan tabel analisis

3. Penentuan Prioritas (Synthesis of Priority)

4. Konsistensi Logis (Logical Consistency) 


\section{METODE PENELITIAN}

\section{Tahapan Penelitian}

Penelitian merupakan kegiatan yang dilakukan secara terencana, teratur, dan sistematis untuk mencapai tujuan tertentu. Tahapan penelitian ini juga merupakan pengembangan dari kerangka penelitian, dan terbagi lagi menjadi beberapa sub menu bagian yaitu dapat dilihat pada gambar berikut

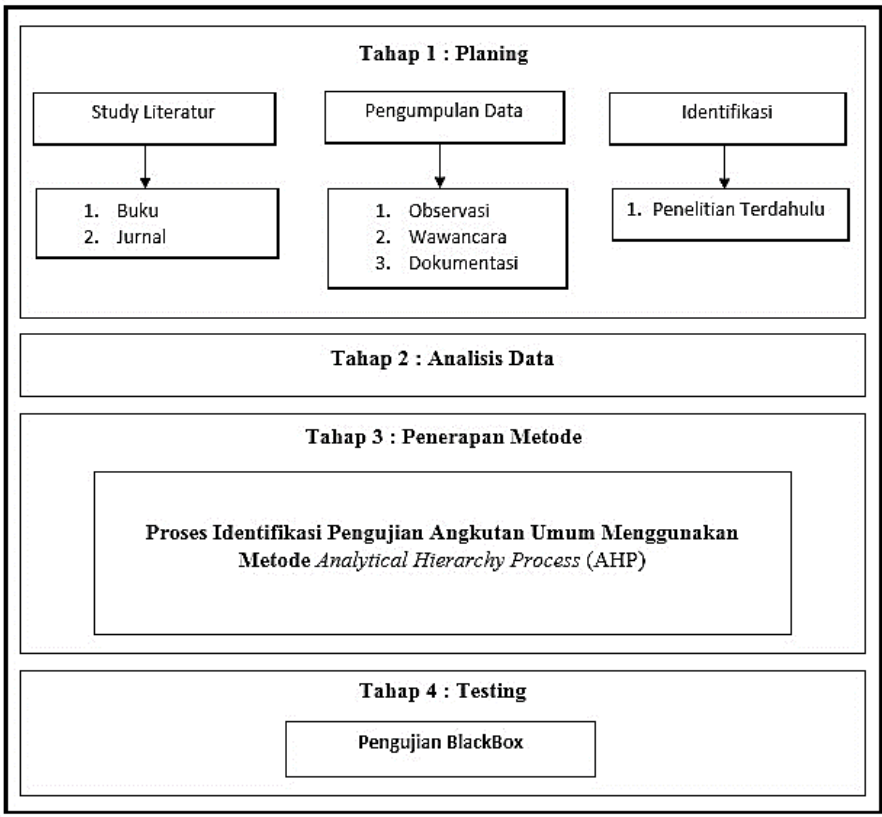

Gambar 1. Tahapan Penelitian

\section{Sample}

Sampel yang digunakan dalam penelitian ini adalah kendaraan yang diuji berdasarkan Nomor 22 tahun 2009 tentang Lalu Lintas dan Angkutan Jalan (PP LLAJ) yaitu : mobil bus, mobil barang, mobil penumpang umum, kreta gandingan, tempelan, dan kendaraan khusus.

\section{Teknik Pengumpulan Data}

Pengumpulan data yang akan dilakukan pada penelitian ini adalah sebagai berikut:

1. Observasi

Pengumpulan data dengan cara mengadakan penelitian dilapangan dengan mengamati kondisi yang terjadi dilapangan, dalam hal ini penulis melakukan observasi pada Dinas Perhubungan Lampung Tengah

2. Wawancara

Metode ini dilakukan dengan cara tanya jawab atau wawancara kepada petugas penguji mengenai permasalahan yang dibahas.

3. Dokumentasi

Dokumentasi dilakukan untuk mendapatkan data yang valid atau sesuai mengenai informasi yang dibutuhkan, dalam hal ini penulis melakukan dokumentasi terhadap gambar tempat penelitian, pengujian kendaraan.

4. Identifikasi

Bertujuan untuk mencari, menemukan, mengumpulkan, meneliti dan mencatat informasi terkait kebutuhan penelitian, yang mengenai penelitian terdahulu seperti definisi masalah dan lingkup penelitian.

\section{Metode Analisis}

Analisis kebutuhan fungsional adalah pernyataan layanan sistem yang harus disediakan, bagaimana sistem bereaksi pada input tertentu dan bagaimana perilaku sistem pada situasi tertentu. Sistem yang dikembangkan harus mempunyai kebutuhan fungsional sebagai berikut :

1. Pengguna dapat mengelola hak akses user. Pada sistem ini admin hanya login, logout, dan kelola account. 
2. Staf registrasi bertugas mengatur data-data pengujian kendaraan bermotor. Pada sistem ini, staf registrasi dapat login, logout, input data kendaraan, dan input data pemilik kendaraan.

3. Penguji Orang yang dapat melihat data kendaraan dan pemilik kendaraan yang akan diuji serta input nilai pengujian. Pada sistem ini penguji dapat login, logout, view data kendaraan bermotor yang akan diuji, input pengujian kendaraan bermotor.

4. Kepala unit pelaksana teknis yang bertugas Orang yang dapat menginput nilai indikator dan dapat melihat laporan pengujian secara.

\section{HASIL DAN PEMBAHASAN}

Implementasi merupakan tahap terakhir dalam desain dan penggabungan kode program, setelah melakukan analisis, perancangan, implementasi beserta pengujian yang telah dilakukan, maka dapat diperoleh sistem pendukung keputusan yang dibangun dapat mempercepat proses pemeriksaan dan verifikasi hasil pengujian fisik kendaraan. Berikut ini merupakan hasil implementasi sistem pendukung keputusan untuk pengujian kelayakan angkutan umum menggunakan metode Analitycal Hierarchy Process.

\section{Tampilan Menu Utama Admin}

Pada menu utama ini juga terdapat menu pilihan halaman dashboard, data pengguna dan keluar.

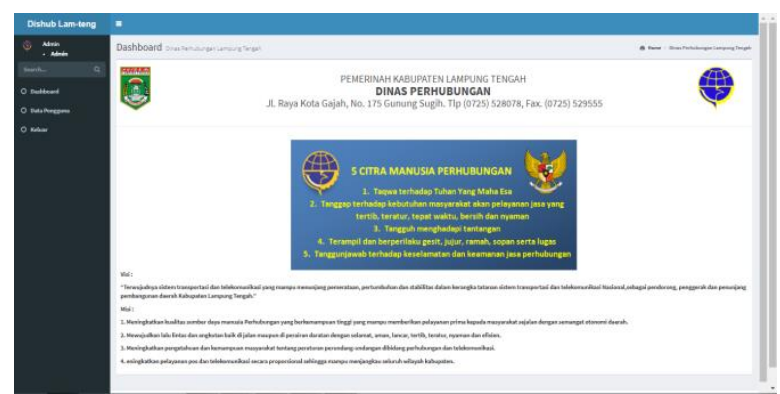

Gambar 2.Tampilan menu utama admin

\section{Tampilan Menu Data Pengujian}

Pada menu ini berisi nama dan no telepon pemilik, no kendaraan dan jenis kendaraan, dan subkriteria dari bagian bagian yang di telah di tentukan menggunakan metode Analytical Hierarcy Process, hasil, keterangan dan tanggal pengujian yang tersimpan di database. Tombol tambah digunakan untuk memulai penilaian pengujian, tombol ubah digunakan untuk merubah penilaian pengujian dan tombol hapus untuk menghapus data pengujian.

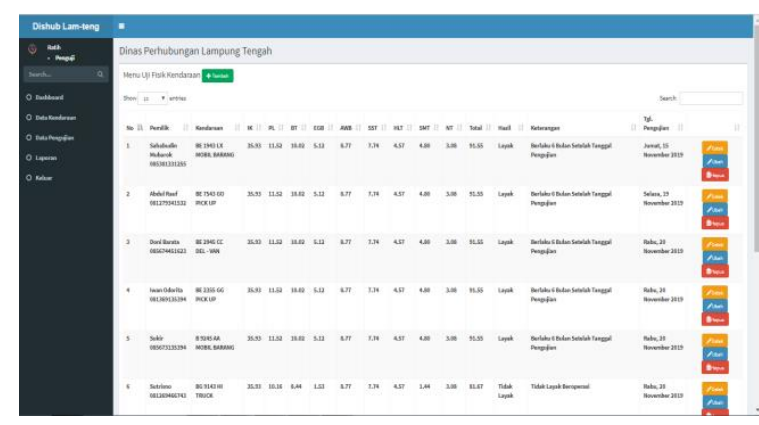

Gambar 3.Tampilan menu data pengujian 


\section{Tampilan Menu Indikator}

Pada halaman menu indikator adalah halaman untuk memasukan nilai-nilai yang telah di buat menggunakan metode AHP.Nilai nilai tersebut yang nantinya dijadikan sebagai nilai subkriteria yang olah untuk menentukan nilai akhir di pengujian kendaraan.

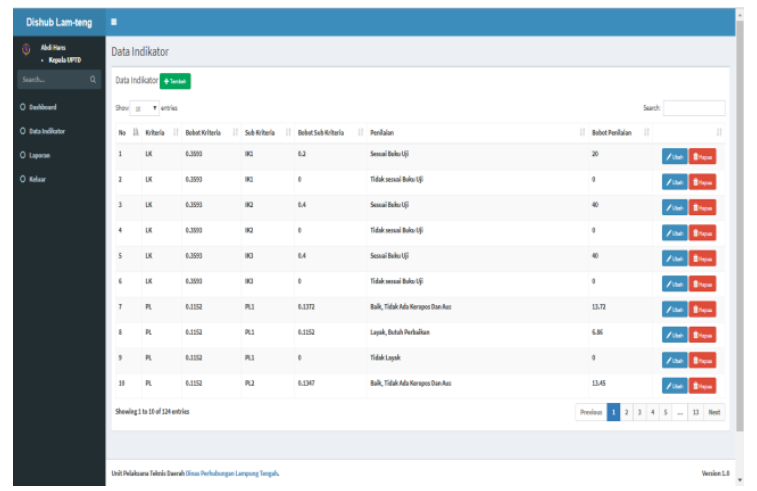

Gambar 4.Tampilan Menu Indikator

\section{Tampilan Laporan Hasil Uji KIR}

Pada tampilan ini hanya kepala unit pelaksana teknis yang dapat mencetak untuk melihat laporan pengujian dalam beberapa periode.

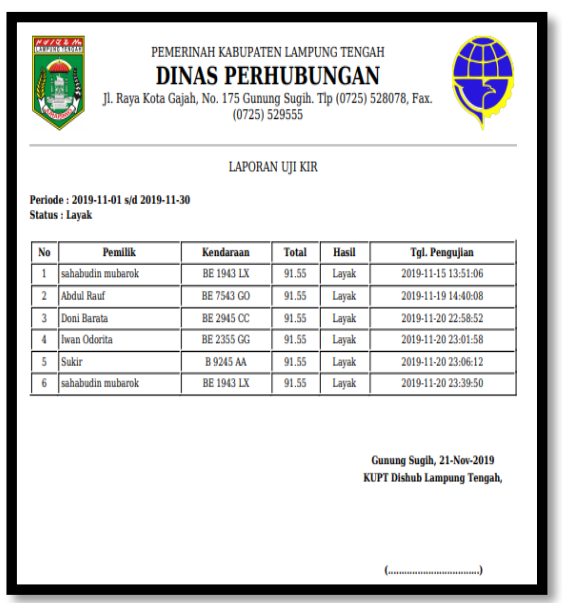

\section{Gambar 5.Tampilan Laporin Hasil Uji KIR}

Nilai pengujian dari hasil perhitungan kriteria dan subkriteria ini akan dapat menentukan hasil layak atau tidak layak dari pengujian kendaraan yang dilakukan serta jenis tindakan yang harus dilakukan sesuai dengan masing-masing kriteria dan subkriteria yang kurang atau belum memenuhi persyaratan hasil pengujian.

Tabel 1. Perhitungan Nilai Kriteria

\begin{tabular}{|c|c|c|c|c|c|c|c|c|}
\hline Kriteria & Bobot & Subkriteria & Bobot & Penilaian & Bobot & Bobot & Bobot & Bobot \\
\hline \multirow{3}{*}{ IK } & \multirow{3}{*}{0,36} & IK1 & 0,5 & Sesuai Buku Uji & 100 & 50,00 & \multirow{3}{*}{100,00} & \multirow{3}{*}{35,93} \\
\hline & & IK2 & 0,25 & Sesuai Buku Uji & 100 & 25,00 & & \\
\hline & & IK3 & 0,25 & Sesuai Buku Uji & 100 & 25,00 & & \\
\hline \multirow{4}{*}{ PL } & \multirow{4}{*}{0,12} & PL1 & 0,14 & Baik, Tidak Ada Keropos Dan Aus & 100 & 13,72 & \multirow{4}{*}{100,00} & \multirow{4}{*}{11,52} \\
\hline & & PL2 & 0,13 & Baik, Tidak Ada Keropos Dan Aus & 100 & 13,45 & & \\
\hline & & PL3 & 0,16 & Baik, Tidak Ada Keropos Dan Aus & 100 & 16,48 & & \\
\hline & & PL4 & 0,11 & Baik, Tidak Ada Keropos Dan Aus & 100 & 11,29 & & \\
\hline
\end{tabular}


Jurnal Informatika dan Rekayasa Perangkat Lunak (JATIKA), Vol: 1, No: 1, 1-8

\begin{tabular}{|c|c|c|c|c|c|c|c|c|}
\hline & & PL5 & 0,13 & Baik, Tidak Ada Keropos Dan Aus & 100 & 13,11 & & \\
\hline & & PL6 & 0,10 & Baik, Tidak Ada Keropos Dan Aus & 100 & 10,12 & & \\
\hline & & PL7 & 0,06 & Baik, Menyala Dengan Baik & 100 & 5,62 & & \\
\hline & & PL8 & 0,03 & Baik, Menyala Dengan Baik & 100 & 3,49 & & \\
\hline & & PL9 & 0,04 & Baik, Menyala Dengan Baik & 100 & 3,89 & & \\
\hline & & PL10 & 0,04 & Baik, Menyala Dengan Baik & 100 & 4,07 & & \\
\hline & & PL11 & 0,05 & Baik, Menyala Dengan Baik & 100 & 4,75 & & \\
\hline \multirow{5}{*}{ BT } & \multirow{5}{*}{0,10} & BT1 & 0,3 & Layak, $>50 \%$ dari berat sumbu 1 & 100 & 29,76 & \multirow{5}{*}{100,00} & \multirow{5}{*}{10,02} \\
\hline & & BT2 & 0,3 & Layak, $>50 \%$ dari berat sumbu 1 & 100 & 29,76 & & \\
\hline & & BT3 & 0,2 & Layak, $>50 \%$ dari berat sumbu 2 dan 3 & 100 & 15,79 & & \\
\hline & & BT4 & 0,16 & Layak, $>50 \%$ dari berat sumbu 2 dan 3 & 100 & 15,79 & & \\
\hline & & BT5 & 0,09 & Layak, $>50 \%$ dari berat sumbu 2 dan 3 & 100 & 8,90 & & \\
\hline \multirow{2}{*}{ EGB } & \multirow{2}{*}{0,10} & EGB1 & 0,50 & $\begin{array}{l}\text { Layak, Ketebalan Asap <70\% (<2010) / } \\
<40 \%(>=2010)\end{array}$ & 100 & 50,00 & \multirow{2}{*}{100,00} & \multirow{2}{*}{10,23} \\
\hline & & EGB2 & 0,50 & $\begin{array}{l}\text { layak, } \mathrm{CO}<=4,5 \text { dan } \mathrm{HC}<=1200(<2007) / \\
\mathrm{CO}<=1,5 \text { dan } \mathrm{HC}<=200(>=2007)\end{array}$ & 100 & 50,00 & & \\
\hline \multirow[t]{3}{*}{ AWB } & \multirow{2}{*}{0,11} & AWB1 & 0,4 & Sesuai Buku Uji & 100 & 40,00 & \multirow{2}{*}{100,00} & \multirow{2}{*}{10,96} \\
\hline & & AWB2 & 0,4 & Sesuai Buku Uji & 100 & 40,00 & & \\
\hline & & AWB3 & 0,2 & Sesuai Buku Uji & 100 & 20,00 & & \\
\hline \multirow{2}{*}{ SST } & \multirow{2}{*}{0,08} & SST1 & 0,4 & Layak, $<=5$ milimeter & 100 & 40,00 & \multirow{2}{*}{100,00} & \multirow{2}{*}{7,74} \\
\hline & & SST2 & 0,4 & Layak, $<=5$ milimeter & 100 & 40,00 & & \\
\hline \multirow{4}{*}{ HLT } & \multirow{4}{*}{0,06} & HLT1 & 0,2 & Layak, >=12000 Cd & 100 & 20,00 & \multirow{4}{*}{80,00} & \multirow{4}{*}{4,57} \\
\hline & & HLT2 & 0,2 & Layak, >=12000 Cd & 100 & 20,00 & & \\
\hline & & HLT3 & 0,2 & Layak, $>=12000 \mathrm{Cd}$ & 100 & 20,00 & & \\
\hline & & HLT4 & 0,2 & Layak, >=12000 Cd & 100 & 20,00 & & \\
\hline SMT & 0,05 & SMT & 1 & Layak, $<=35 \mathrm{~km} / \mathrm{h}$ & 100 & 100,00 & 100,00 & 4,81 \\
\hline NT & 0,03 & NT & 1 & Layak, $50 \mathrm{db}-130 \mathrm{db}$ & 100 & 100,00 & 100,00 & 3,08 \\
\hline
\end{tabular}

Nilai : $0,36 *((0,2 * 100)+(0,40 * 100)+(0,40 * 100))+0,12 *((0,14 * 100)+(0,13 * 100)+(0,16 * 100)+$ $(0,11 * 100)+(0,13 * 100)+(0,10 * 100)+(0,06 * 100)+(0,03 * 100)+(0,04 * 100)+(0,04 * 100)+$ $(0,05 * 100))+0,10 *((0,3 * 100)+(0,3 * 100)+(0,2 * 100)+(0,16 * 100)+(0,09 * 100))+0,10 *((0,50 * 100)$ $+(0,50 * 100))+0,11 *((0,4 * 100)+(0,4 * 100)+(0,2 * 100))+0,08 *((0,50 * 100)+(0,50 * 100))+0,06 *$ $((0,2 * 100)+(0,2 * 100)+(0,22 * 100)+(0,22 * 100))+0,05+0,03=35,93+11,52+10,02+10,23+10,96$ $+7,74+4,57+4,81+3,08=98,86$

\section{Keterangan hasil pengujian :}

Layak : Nilai Perhitungan $\geq 98,86$

Perlu Perbaikan : Nilai Perhitungan > 91,55 sampai 87

Tidak Layak dan Sangat Perlu Perbaikan : Nilai Perhitungan dibawah 87 


\section{Pengujian Terhadap Aspek Functionality}

Tabel 2. PengujianAspekFunctionality

\begin{tabular}{|c|c|c|c|c|c|c|c|c|c|c|}
\hline \multicolumn{3}{|c|}{ Kriteria } & 番 & $\mathscr{H}$ & $\underset{\simeq}{\mathscr{\Xi}}$ & $\omega$ & क & \multirow{2}{*}{ 这 } & \multirow{2}{*}{ 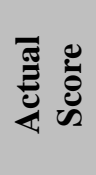 } & \multirow{2}{*}{ ฮ્ّ } \\
\hline \multicolumn{3}{|c|}{ Bobot } & 1 & 2 & 3 & 4 & 5 & & & \\
\hline \multirow{4}{*}{ 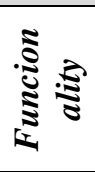 } & \multirow{2}{*}{ Appropriateness } & 1 & $\mathbf{0}$ & $\mathbf{0}$ & $\mathbf{0}$ & 1 & 3 & 4 & 16 & 20 \\
\hline & & 2 & $\mathbf{0}$ & $\mathbf{0}$ & $\mathbf{0}$ & 4 & 1 & 4 & 20 & 20 \\
\hline & \multirow{2}{*}{ Accuracy } & 3 & $\mathbf{0}$ & $\mathbf{0}$ & $\mathbf{0}$ & 2 & 2 & 4 & 16 & 20 \\
\hline & & 4 & $\mathbf{0}$ & $\mathbf{0}$ & $\mathbf{0}$ & 3 & $\mathbf{1}$ & 4 & 16 & 20 \\
\hline \multicolumn{3}{|c|}{ Total } & & & & & & & 68 & 80 \\
\hline
\end{tabular}

$$
\text { Result }=\frac{68}{80} \times 100 \%=85 \%(\text { Very Good })
$$

Berdasarkan hasil tanggapan responden terhadap aspek functionality pengujian aplikasi system pendukung keputusan pengujian kelayakan angkutan umum mendapatkan nilai persentase sebesar $85 \%$ dan masuk dalam kriteria sangat baik (very good).

\section{Pengujian Terhadap Aspek Performance Efficiency}

Tabel 3. PengujianAspekEfficiency

\begin{tabular}{|c|c|c|c|c|c|c|c|c|c|c|}
\hline \multicolumn{3}{|c|}{ Kriteria } & 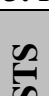 & $\mathscr{H}$ & 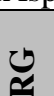 & $\omega$ & $\mathscr{\infty}$ & \multirow{2}{*}{ 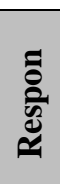 } & \multirow{2}{*}{ 焉 } & \multirow{2}{*}{ 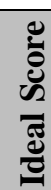 } \\
\hline \multicolumn{3}{|c|}{ Bobot } & 1 & 2 & 3 & 4 & 5 & & & \\
\hline \multirow{3}{*}{$\underbrace{\stackrel{0}{0}}_{\mathbb{N}}$} & \multirow{2}{*}{ Time Behaviour } & 5 & $\mathbf{0}$ & $\mathbf{0}$ & 2 & $\mathbf{0}$ & 2 & 4 & 16 & 20 \\
\hline & & 6 & $\mathbf{0}$ & $\mathbf{0}$ & 1 & 2 & 1 & 4 & 16 & 20 \\
\hline & Resource Utilization & 7 & $\mathbf{0}$ & $\mathbf{0}$ & 1 & 1 & 1 & 4 & 12 & 20 \\
\hline \multicolumn{3}{|c|}{ Total } & & & & & & & 44 & 60 \\
\hline
\end{tabular}

$$
\text { Result }=\frac{44}{60} \times 100 \%=73,3 \%(\text { Good })
$$

Berdasarkan hasil tanggapan responden terhadap aspek efficiency pengujian aplikasi sIstem pendukung keputusan pengujian kelayakan angkutan umum mendapatkan nilai persentase sebesar 73,3\% dan masuk dalam kriteria baik (good).

\section{Pengujian terhadap aspek operability}

\begin{tabular}{|c|c|c|c|c|c|c|c|c|c|c|}
\hline \multicolumn{3}{|c|}{ Kriteria } & 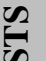 & $\tilde{\omega}$ & $\underset{\simeq}{0}$ & $\omega$ & $\mathscr{2}$ & \multirow{2}{*}{ 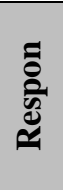 } & \multirow{2}{*}{ 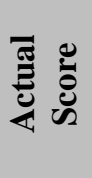 } & \multirow{2}{*}{ 苞 } \\
\hline \multicolumn{3}{|c|}{ Bobot } & 1 & 2 & 3 & 4 & 5 & & & \\
\hline \multirow{3}{*}{$=$} & $\begin{array}{c}\text { Appropriateness } \\
\text { Recognisability }\end{array}$ & 8 & $\mathbf{0}$ & $\mathbf{0}$ & 1 & 2 & 1 & 4 & 16 & 20 \\
\hline & Learnability & 9 & $\mathbf{0}$ & $\mathbf{0}$ & $\mathbf{0}$ & 3 & 1 & 4 & 17 & 20 \\
\hline & Ease of use & 10 & $\mathbf{0}$ & $\mathbf{0}$ & $\mathbf{0}$ & 2 & 2 & 4 & 18 & 20 \\
\hline
\end{tabular}

Tabel 4. PengujianAspekOperability 


\begin{tabular}{|c|c|c|c|c|c|c|c|c|c|c|}
\hline Helpfulness & 11 & 0 & 0 & 0 & 2 & 2 & 4 & 18 & 20 \\
\hline Attractiveness & 12 & 0 & 0 & 2 & 2 & 0 & 4 & 14 & 20 \\
\hline $\begin{array}{c}\text { Technical } \\
\text { Accessibility }\end{array}$ & 13 & 0 & 0 & 3 & 1 & 0 & 4 & 13 & 20 \\
\hline $\begin{array}{r}\text { Total } \\
\hline\end{array}$ & & & & 96 & 120 \\
\hline
\end{tabular}

$$
\text { Result }=\frac{96}{120} \times 100 \%=80 \%(\text { Good })
$$

Berdasarkan hasil tanggapan responden terhadap aspek operability pengujian aplikasi system pendukung keputusan pengujian kelayakan angkutan umum mendapatkan nilai persentase sebesar $80 \%$ dan masuk dalam kriteria baik (good).

\section{SIMPULAN}

Berdasarkan hasil penelitian yang telah dilakukan, maka kesimpulan penelitian yang berjudul sistem pendukung keputusan pengujian kelayakan angkutan umum, yaitu:

1. Sistem pendukung keputusan yang dibangun dapat membantu proses pengolahan data pengujian fisik kendaraan, dan Sistem pendukung keputusan yang dibangun dapat mempercepat proses pemeriksaan dan verifikasi hasil pengujian fisik kendaraan

2. Pengujian dilakukan sebagai evaluasi kualitas software, aspek functionality, aspek efficiency, dan aspek operability. Skor total yang dihasilkan dari pengujian ini yaitu aspek functionality adalah 85\%, aspek efficiency adalah $73,3 \%$ dan aspek operability adalah $80 \%$

\section{UCAPAN TERIMA KASIH}

Puji syukur penulis panjatkan kepada Allah SWT, karena atas berkat dan rahrnat-Nya, penulis dapat menyelesaikan dengan judul "Sistem Pendukung Keputusan Pengujian Kelayakan Angkutan Umum Menggunakan Metode Analytical Hierarchy Process".

1. Bapak Dr. H.M. Nasrullah Yusuf, S.E., M.B.A. selaku Rektor Universitas Teknokrat Indonesia.

2. Bapak Dr. H. Mahathir Muhammad, S.E., M.M. selaku Dekan Fakultas Teknik dan Ilmu Komputer Universitas Teknokrat Indonesia.

3. Ibu Dyah Ayu Megawaty, M.Kom., selaku Ketua Program Studi S1 Informatika Fakultas Teknik dan Ilmu Komputer Universitas Teknokrat Indonesia.

\section{REFERENSI/DAFTAR PUSTAKA}

Borman, R.I., Megawaty, D. A., Attohiroh, A. 2020. Implementasi Metode TOPSIS Pada Sistem Pendukung Keputusan Pemilihan Biji Kopi Robusta Yang Bernilai Mutu Ekspor (Studi Kasus: PT. Indo Cafco Fajar Bulan Lampung). Fountain of Informatics Journal.

Damayanti. 2020. Sistem Informasi Pendistribusian Barang Bengkel Las dan Advertising Menggunakan Model SCM. Jurnal Komputer dan Informatika.

Irawan, A., Rohaniah, R., Sulistiani, H., Priandika, A. T. 2019. Sistem Pendukung Keputusan Untuk Pemilihan Tempat Servis Komputer di Kota Bandar Lampung Menggunakan Metode AHP. Jurnal Tekno Kompak.

Kusrini, 2007. Konsep dan Aplikasi Sistem Pendukung Keputusan. C.V Andi. Yogyakarta: s.n.

Magdalena, H., 2012. Sistem Pendukung Keputusan Untuk Menentukan Mahasiswa Lulusan Terbaik Di Perguruan Tinggi (Studi Kasus Stmik Atma Luhur Pangkalpinang, Issue Seminar Nasional Teknologi Informasi dan Komunikasi 2012.

Riskiono, S. D., Pasha, D. 2020. Analisis Metode Load Balancing Dalam Meningkatkan Kinerja Website E-Learning. Jurnal Teknoinfo.

Sucipto, A., Fernando, Y., Borman, R. I., Mahmuda, N. 2019 .Penerapan Metode Certainty Factor Pada Diagnosa Penyakit Saraf Tulang Belakang.

Taufiq, R. \& Fahrozi, N. F., 2016. Perancangan Sistem Pendukung Keputusan (SPK) Pemilihan Kendaraan Alat Berat Tambang Batubara dengan Metode Analytical Hierarchy Process (AHP), Volume 3(scientium), p. No.5.

Turban. 2012. Decision Support System. Yogyakarta: Andi Offset

Wantoro, A. 2020. Kombinasi Metode Analitical Hierarchy Process (AHP) dan Simple Addive Weight (SAW) UNTUK Menentukan Website E-Commerce Terbaik. SISTEMASI: Jurnal Sistem Informasi, 2020

Warpani, S., 2002. Merencanakan Sistem Perangkutan. Bandung: Penerbit ITB. 